\title{
Г.С. Рагозин
}

\section{«СОЦИАЛИСТИЧЕСКАЯ ПРУССИЯ»? РАЗРУШЕНИЕ И РЕАБИЛИТАЦИЯ «ПРУССКОГО МИФА» В ГДР (1945-1990 гг.)}

\begin{abstract}
Статья посвящена исторической политике ГДР, а именно динамике изменения в ней статуса «Прусского мифа» как совокупности нарративов, формирующих образ одного из наиболее весомых германских государств нового времени - королевства Пруссия. Данная проблема являлась чувствительной для идеологии и пропаганды СЕПГ в силу необходимости переформатирования исторического нарратива и поддержки немецкой идентичности в республике посредством целого комплекса мероприятий, и формирования образа республики для стран западного блока. Место «прусского мифа» в идеологии и пропаганде ГдР претерпело значительные изменения за 41 год существования республики, от негативизма до закрепления внешнего образа «социалистической Пруссии» а последствия этой политики оказывают влияние на «прусский миф» в Германии и поныне.

Ключевые слова: история ГДР; «Прусский миф»; историческая память; историческая политика ГДР; «Социалистическая Пруссия».
\end{abstract}

Роль исторического мифа в государственной идеологии, исторической памяти и политическом сознании представляет актуальную тему, поскольку миф функционирует как корпус нарративов и образов, тиражируемых для обоснования права общности на существование. В рамках концепции тоталитаризма, применяемой к ряду политических режимов, принято говорить о всепроникающей общественную жизнь идеологии, которая является основой для системы власти. Одной из ее опор в формировании образа прошлого и выступает заданный нарратив, базируемый на определенных мифах или их интерпретациях. При этом идеологи могут пытаться опровергнуть существовавшие до этого нарративы либо инкорпорировать их в идеологию и пропаганду с целью легитимации режима или подчеркивания обособления новой общности от старой. Данная составляющая исторической политики принимает в ряде случаев радикальные формы. Для реализации заявленных тезисов используются средства исторической науки, масс-медиа, перестройки городского пространства, массовой культуры, музейного дела. Исчезновение персоналий и явлений или их возвращение было связано с изменением понимания национальной идентичности и стремлением держать ее трактовки в рамках идеологии с помощью переработки наследия.

Ярким примером является Германская Демократическая Республика. Наиболее болезненным для официальной идеологии страны оставался вопрос о прусском наследии $[1,2]$. За период Второй мировой войны сформировался образ прусского государства как предшественника Третьего Рейха. Это было связано и с тем, что идеологи нацистского периода обращались к «прусскому мифу»- системе нарративов, нацеленной на поддержание образа королевства Пруссия, а также связанных с ним элементов как основополагающих для немецкой национальной идентичности. Несмотря на то, что этот миф включал в себя интеллектуальное, политическое, правовое и культурное наследие, за период
1939-1945 гг., а также с учетом представлений вне Германии и с принятием во внимание того, что прусское военное наследие активно эксплуатировалось НСДАП, это привело к осуждению королевства Союзной контрольной комиссией в 1947 г. [3, 4].

С оформлением ГДР ее руководство исходило из негативизма в отношении «прусского» [5]. На официальном уровне тиражировались преемственность от него нацистского режима, реакционный характер политической практики и изначально высокая роль военных [6]. Это дополнялось демонтажем памятников. Положение осложнялось тем, что часть прусских земель оказалась в составе ПНР и СССР. Это усложняло поддержание исторической памяти о королевстве. При этом Пруссию часто упоминали в контекстах, где она соседствовала с Третьим Рейхом [7; 8. S. 217-218]. Особенно это касалось сюжетов, где их преемстенность виднелась очевидной: военная история, политическая традиция. Этот образ тиражировался в средствах массовой информации, как центральных [9], так и региональных [10]. Эти же документы обосновывали формирование нового городского пространства, свободного от «Замковой истории» [10], «следов милитаризма и реакции». Итогом этого и стал снос Городского дворца и Гарнизонной церкви в Потсдаме, озаглавленный как «Триумф над духом Потсдама» [11].

В процессе демонтажа прусского наследия принимали участие такие историки, как Виллибальд Гуче, который охарактеризовал прусское наследие как «фредерицианскую философию грабежа», а направление кинематографа Fredericus Rex как «литье воды на мельницу империалистов - поджигателей войны» [12]. Официальным закреплением попытки выстроить немецкую идентичность на социально-групповой солидарности стала конституция ГДР 1949 г. [13] Фактически, это была легитимация новой идентичности с марксизмом-ленинизмом-сталинизмом в основе [2]. При этом подчеркивалось, что ФРГ переняла негативные 
черты «старого режима». В партийной печати публиковались такие материалы, как «Слава Пруссии на службе НАТО», которые подчеркивали то, что руководство блока потворствует возрождению «духа Потсдама» [14]. Запрет на прусскую тематику продержался до начала 1970-х гг., хотя отступления от негативизма начались в 1950-е гг.: например, в 1953 г. прошел вечер памяти Г. Шарнхорста, растиражированный в печати [15]. На нем реформатора обозначили как «патриота», что означало попытку инкорпорации памяти о прусских военных в официальную идеологию [16]. Более того, при создании Национальной народной армии ГДР форма сохранила старую символику [7]. С момента создания ННА позиционировалась как продолжатель традиций борьбы за освобождение Германии 18131814 гг. [5. S. 186]. В музейном деле ГДР линия истории была показана материалами Музея германской истории в бывшем здании Арсенала (ныне - Германский исторический музей). В схожем формате предстала и «Новая вахта»: военный памятник был заменен на скульптуру «Пьета». Такое переформатирование означало попытку оттеснить прусскую составляющую на второй план. Примером отступления от критики прусского наследия стало переименование Берлинского университета в Университет имени Гумбольдта в Берлине. Фактически, это было признание роли братьев Гумбольдт в интеллектуальном и политическом наследии Германии.

Изменение подхода к «прусскому наследию» началось во второй половине 1960-х гг. Первыми шагами стали учреждение орденов Шарнхорста и Блюхера [17], а в газете Neues Deutschland был опубликован ряд материалов о Г. Шарнхорсте под редакцией Х. Хелмерта. С этого момента миф о военных - основоположниках «народной армии» и «народной войны» стал частью партийного и государственного мифотворчества. Со сменой руководства в ГДР эти изменения расширились: Э. Хонеккер продолжил наращивание позиций «прусского» в идеологии и пропаганде. С учетом изменений в германо-германских отношениях отпала необходимость в прежней модели репрезентации Пруссии. Незадолго до этого была принята новая конституция, в которой ГДР провозглашалась «социалистическим государством немецкой нации». Таким образом, идеологи стали воспринимать общность граждан как основанную на национальной принадлежности в социалистическом ключе [18]. Это было противодействием тезису «Zwei Staate - eine Nation» в ФРГ [19]. По сути, это означало соперничество за лидерство в объединении страны, и историческое наследие было одним из аргументов для идеологов ЦК СЕПГ. Это привело к выходу образов Пруссии в кинематограф и телевидение.

Первым из таковых стал фильм «Lützower» В. Вальрота (1972 г.). Лента была посвящена войне за освобождение Германии в 1813 г. В качестве основы для сюжета был взят миф о Фрайкоре майора фон Лютцова, развернувшего борьбу против французских войск в Германии. Основное внимание отдавалось прусским военным и их сподвижникам, которые предстали как члены национального движения. Этим было начато тиражирование мифа о Пруссии как одном из ключевых участников освобождения Германии в 18131814 гг., а также основной площадки для дискуссии о создании немецкого национального государства [20]. Вторым проектом стал сериал «Scharnhorst» режиссера В.-Д. Пансе, посвященный событиям Наполеоновских войн и реформ в Пруссии 1807-1814 гг. (1978 г.). Авторам предстояло работать не только с образами деятелей национального движения, но и генералитета, высшего руководства и монархии Гогенцоллернов. Одно их включение в идеологию шло вразрез с оценками марксистской исторической науки. С реинтеграцией военных и гражданских реформаторов начала XIX в. в мифотворчество внимание со стороны ЦК СЕПГ к проекту было повышенным, что подтвердило возвращение памятников на их исторические места в Берлине.

Работа над сериалом началась в 1972 г. при содействии военного историка Х.-Ю. Усчека. Сюжет сериала был драматическим, выстроенным на основе мифа о противодействии короля и высшего дворянства реформаторам, о подъеме национально-освободительного движения, и, особенно, распространению его идей реформаторами [20]. В сравнении с предыдущей картиной прослеживается привлечение «Прусского мифа» как этики службы государству и обществу. Образ реформаторов был выстроен на контрасте с их предшественниками и «несвободой» большинства населения. В фильме получили освещение идеи «народной армии» и обращения государства к жизни нации, что является маркером того, что в ГДР реформаторов 1807-1814 гг. отразили в качестве «предшественников» республики и силы общественного прогресса [21]. Говоря о прусской тематике в кинематографе, следует отметить, что тезис о реакционности «прусского милитаризма» отпал [2]. Это ставило под вопрос дальнейшее развитие исторической политики СЕПГ. Оба проекта были нацелены на манипуляцию общественным мнением. Реплики часто содержали марксистскую лексику: «национальная народная армия», «разрушить старое, чтобы создать новое». В сериале фигурировало российско-прусское «братство по оружию». 1970-е гг., в итоге, стали возвращением «прусского» в немецкую национальную идентичность в ГДР [21]. Заказ СЕПГ на тиражирование образов ключевых фигур был выполнен, доказательством чему послужила рекомендация использовать сериал в преподавании истории в школе.

Одновременно возросло число публикаций и мероприятий по прусской истории. Из числа гражданских историков следует отметить работы И. Миттенцвай, посвященные Фридриху II. В них монарх, с одной стороны, предстал в апологетическом ключе. С другой стороны, политика Фридриха после Семилетней войны подверглась критике за невнимание к перспективам, что привело к катастрофе 1806 г. [23]. Военные историки Х.-Ю. Усчек, Х. Хелмерт и О. Грелер инкорпори- 
ровали короля, его наследие и реформаторов начала XIX в. в воинскую традицию, что свидетельствует о соперничестве Бундесвера и ННА за преемственность от «старой немецкой армии» [24-26]. В этом плане у ЦК СЕПГ было преимущество в связи с возможностью использовать элементы, которые остались географически в ГДР. Началось восстановление памятников, посвященных прусским деятелям: вернулись на свои места памятники, возобновились реставрационные работы во дворцах Потсдама и в Берлине. Это привело к тому, что представители западных стран стали представлять ГДР более «национальным» немецким государством, чем ФРГ, что воспринималось в ЦК СЕПГ как успешное создание внешнего образа «Социалистической Пруссии» $[27,28]$.

Достижения исторической науки ГДР в изучении истории Пруссии становились объектом публикаций в партийной печати: отметились такие историки, как К.Х. Борнер, Ю. Вильке, А. Лашитца, К.-Х. Тиманн, Х. Кете, Г. Ленцер, Х. Вессель, Р. Отте, Й. Петцольд, В. Мюллер. Особое внимание стало уделяться социальным и правовым реформам в королевстве [29], а также научным мероприятиям, посвященных прусской тематике [30-32]. При этом публиковались объявления о выходе научных и научно-популярных работ [33] для охвата членов СЕПГ данной проблематикой. Участие в этом принимали сотрудники архивов, расположенных в ГДР [32]. Началось переиздание трудов прусских военных теоретиков [34], а также тиражирование концепции «народной войны». Противовесом от ФРГ стала выставка «Preußen - Versuch einer Bilanz», ставшая частью Прусской выставки в 1981 г. Последствием стало усиление академической переработки прусского наследия. «Соперничество за Пруссию» шло в условиях кризиса в соцлагере: ГДР искала возможности для проведения самостоятельной от СССР внешней политики. Растущие связи между германскими государствами усилили признание ГДР на международной арене, и использование прусской традиции стало одним из катализаторов успеха, который СЕПГ считала своим.

Тем не менее, монополия прусской традиции в ГДР вызвала недовольство в Саксонии. С целью примирения традиций ЦК СЕПГ заказал сериал «Sachsens Glanz und Preußens Gloria» под руководством режиссера Х.И. Каспжика. Фильм обратился к повседневности королевских дворов, придворным интригам, дипломатии и внешней политике, взаимоотношениям государств - предшественников ГДР. Однако главной целью сериала в 1982 г. было заявлено представление образов «прогрессивных» Пруссии и Саксонии в ключе их «сопротивления внешнему воздействию», под которым понимались монархия Габсбургов, Франция и, в меньшей степени, Россия [35]. Такой образ должен был обосновывать право ГДР на самостоятельную политику. Главными фигурами сериала стали курфюрст Саксонии и король Польши Август II, король Пруссии Фридрих II и персоналии их окружения. Сериал пре- следовал задачу популяризации их истории посредством визуальных образов. Однако марксистская идеология и здесь оставила отпечаток: отразились концепции «абсолютизма» и «классовой борьбы». Последняя часть сериала - «Aus dem Siebenjährigen Krieg» - реабилитировала прусскую тематику в ГДР окончательно: фигура Фридриха II является одной из основных. Хотя, в противовес нацистскому кинематографу образ короля на поле боя представлен меньше. Этим формировался образ авторитарного, но нацеленного на службу государству правителя. Это, с одной стороны, шло вразрез с даже с компромиссными оценками в историографии ГДР [2]. С другой стороны, было уделено внимание Саксонии, что отвечало задаче представления обеих областей как равных в культурном и политическом контекстах истории Германии. Следует отметить то, что эти фильмы получили признание в Германии и после 1990 г.

Тем не менее, несмотря на интеграцию «прусского» в идеологию и пропаганду СЕПГ, следует сказать, что оно сыграло роль и в крушении ГДР. Республике изначально удавалось перехватить инициативу в обосновании своих позиций, однако с учетом ряда факторов ГДР и СЕПГ стало затруднительно конкурировать с ФРГ. Это было связано с дефицитом средств на восстановление памятников, что привело к их утрате. Следующей проблемой стала неоднозначная реакция на возрождение «прусских» элементов в странах соцлагеря $[36,37]$. Негативизм в отношении «прусского мифа» в ГДР оказался избирательным и недолгим. Даже с учетом ведения пропагандистских кампаний и использования исторической науки для критики «прусского мифа» и его устранения из позитивной памяти, исключить его из общественной и политической жизни не удалось. Это создало условия для реабилитации «прусского мифа», которая началась в 1950-е, обозначилась в 1960-е и продолжилась как один из главных элементов идеологии и пропаганды при Э. Хоннекере. Для достижения поставленной цели - восстановления Пруссии как одной из центральных составляющих мифотворчества и идеологии - были задействованы значительные средства. «Реабилитированный прусский миф» опирался на образы государства - борца против гегемонии держав, определяющих европейскую политику, проводника в жизнь прогресса, а также государства - обладателя действительно народной армии (начиная с XIX в.).

Несмотря на амбициозный характер данного проекта, он во многом провалился по причине непринятия во внимание традиций остальных земель, бывших в составе ГДР, несовместимости оценок прусских деятелей с официальными тезисами об осуждении «милитаризма и реакции», а с 1970-х - и конкуренции с ФРГ за право преемственности позитивных черт Пруссии в исторической памяти. Даже образ «Социалистической Пруссии», тиражируемый в западных странах, а также тезис «социализма национальных цветов ГДР» оказались недостаточными для включения «прусского наследия» и «прусского мифа» в идеологию и пропаганду респуб- 
лики. Тем не менее многие из данных наработок были подхвачены в Германии после 1990 г. и стали основой для включения «прусского мифа» в иных трактовках после объединения страны.

\section{ЛИТЕРАТУРА}

1. Данн О. Нации и национализм в Германии, 1770-1990. СПб., 2003.

2. Orlow D. The GDR's failed search for a National Identity, 1945-1989 // German Studies Review. Oct., 2006. Vol. 29 , № 3. P. $537-558$.

3. Mitteilung über die Dreimächtenkonferenz von Berlin (Potsdamer Abkommen) vom 2. August 1945. URL: http://www.documentarchiv.de/in/1945/ potsdamer-abkommen.html (16.01.2015).

4. Gesetz Nr. 46 des Alliierten Kontrollrates in Deutschland über die Auflösung des Staates Preußen, 25. Februar 1947. URL: https://www.1000dokumente.de/pdf/dok_0231_pre_de.pdf(30.07.2018).

5. Bauer F.H. Bundeswehr und Nationale Volksarmee in der Aufstellungsphase 1947 bis 1956. Eine vergleichende Studie. Dissertation. Frankfurt-amMain, 1999.

6. Neues Deutschland. 1.03.1947.

7. Бетмакаев А.М. На пути к восточногерманской идентичности: В. Ульбрихт и отношения между ГДР и СССР в 1949-1964 гг. // Американские исследования в Сибири. Томск : Изд-во Том. гос. ун-та, 2003. Вып. 7. URL: http:/hist.asu.ru/aes/gdr/btmkv.htm (дата обращения: 12.08.2018).

8. Münkler H. Die Deutschen und ihre Mythen. Berlin, 2009. 607 s.

9. Neues Deutschland. 16. Juni 1948.

10. Märkische Volksstimme. 14.11.1959.

11. Märkische Volksstimme. 25.05.1968.

12. Das Volk. 27.01.1962.

13. Verfassung der Deutschen Demokratischen Republik vom 7. Oktober 1949. URL: http://www.verfassungen.de/de/ddr/ddr49-i.htm. (Accessed: 17.07.2018).

14. Neues Deutschland. 15.06.1962.

15. Neues Deutschland. 09.06.1953.

16. Neues Deutschland. 12.02.1966.

17. Protokoll der Sitzung des Nationalen Verteidigungsrates von 13.10.1965. URL: http://www.nationaler-verteidigungsrat.de/downloads/findbuch.pdf. (Accessed: 17.07.2018).

18. Verfassung der Deutschen Demokratischen Republik vom 9. April 1968. URL: http://www.verfassungen.de/de/ddr/ddr68-i.htm. (Accessed: 19.07.2018)

19. Wippermann W. Preußen: kleine Geschichte eines großen Mythos. Freiburg im Breisgau. 2011. $194 \mathrm{~s}$.

20. Wiechmann G. Das Preußenbild in der DDR-Medien: DEFA-Spielfilm „Lützower“// Waterkamp R. (Hg.). Der Wandel des Preußenbildes in den DDR-Medien. Bonn: Bundeszentrale für politische Bildung, 1997. S. 49-70.

21. Mayers P. Die DDR-Fernsehproduktion „Scharnhorst“// Waterkamp R. (Hg.). Der Wandel des Preußenbildes in den DDR-Medien. Bonn : Bundeszentrale für politische Bildung, 1997. S. 70-84.

22. Mittenzwei I. Friedrich II. von Preußen. Eine Biographie. Berlin, 1979. $250 \mathrm{~s}$.

23. Neues Deutschland. 12.05.1971.

24. Gröhler O. Die Kriege Friedrichs II. Berlin, 1981. $245 \mathrm{~s}$.

25. Helmert H., Usczeck H. Preußischdeutsche Kriege von 1864 bis 1871 . Berlin, 1975. 395 s.

26. Русь Э.В. Историческая преемственность как элемент национальной идентичности в историографии ФPГ и ГДР. URL: http://www.rusgermhist.ru/documents/isledovateli/feling/Kontinuitat2.pdf (дата обращения: 15.07.2018).

27. Петелин Б.В., Степанов Г.В. Эрих Хонеккер // Вопросы истории. 2013. № 9. С. 117-128.

28. Ash T.G. Bei den Roten Preußen: wie ein Engländer die DDR erlebt (III) // Spiegel. 16.11.1981. S. 196-208.

29. Neues Deutschland. 05.06.1980.

30. Neues Deutschland. 12.11.1983.

31. Neues Deutschland. 29.09.1986

32. Neues Deutschland. 21.07.1984

33. Neues Deutschland. 16.01.1988.

34. Neues Deutschland. 15.09.1981.

35. Spinder S. Preußen in den DDR-Medien, dargestellt am Beispiel von „Sachsens Glanz und Preußens Gloria“// Der Wandel des Preußenbildes in den DDR-Medien. Bonn : Bundeszentrale für politische Bildung, 1997.

36. Гинцберг Л.И. Фридрих II // Вопросы истории. 1988. № 11. С. 98-118.

37. Thum G. "Preußen - das sind wir!“: Zur Wiederentdeckung der preußischen Kulturlandschaft in Deutschland und Polen // Zeitschrift für Ostmitteleuropa-Forschung. 2010. № 59. Hf. 3. S. 301-322.

German S. Ragozin. Northern (Arctic) Federal University named after M. V. Lomonosov (Arkhangelsk, Russia). E-mail: gragozin92@gmail.com

"SOCIALIST PRUSSIA"? DESTRUCTION AND REHABILITATION OF THE "PRUSSIAN MYTH" IN THE GDR (19451990)

Keywords: GDR history; "Prussian myth"; historical memory in Germany; historical policy of the GDR; "Socialist Prussia".

The paper deals with the GDR historical policy, with an emphasis on dynamics of "Prussian myth" as a complex of narratives forming an image of the Kingdom of Prussia as one of the most influent German states of modern era. The purpose of the paper is to give an assessment to the evolution dynamics of the "Prussian myth" status in ideology, propaganda and mass culture of the republic, and its influence on "new German national identity" within the period between 1949 and 1990.

The following sources became subject to study: printed media (predominantly SED newspaper "Neues Deutschland", and also regional newspapers as "Märkische Volksstimme" and "Das Volk"); National Defense Council meeting minutes, Constitutions of the GDR from 1949 and 1968 (and its renewed version from 1974); movies and TV series shot in the GDR and referring to history of Prussia and its role in Germany; major works of GDR historians devoted to Prussian history; publications on these issues in West German media (e.g. "Der Spiegel"), also referring to an image of the GDR as "Socialist Prussia" through the eyes of the non-German tourist.

Negativism towards "Prussian myth" and "Prussian heritage" was selective during the first two decades of existence of GDR, and mostly demonstrative, aimed to suppress the status of Prussia in the GDR history. Exclusion of Prussia from German history in GDR failed during Walther Ulbricht's regime, evolving into resurrection of "Prussian" elements in National People's Army first, and then into integration of the historical narratives dealing with Prussian history into ideology, propaganda and myth-making, often placing Prussia 
higher, than other East German provinces having a statehood experience. A "resurrected Prussian myth" referred to an image of a German state struggling against the dominance of continental powers, an image of a state turning the ideas of progress, equality and reforms into practice and obtaining a really people's army (since the early $19^{\text {th }}$ century). SED and its propaganda started using the historical and intellectual heritage of the kingdom as a positive element of East German historical memory.

Nevertheless, this ambitious project did not succeed due to strengthening the ambivalence of SED ideology and growing competition with West Germany for the right to proclaim itself a successor of Prussian positive heritage. Despite that fact, it contributed to attempts of Erich Honecker to establish an independent foreign policy of GDR within Socialist Bloc, also contradicting to the USSR postulates (e.g. Brezhnev doctrine) in such issues as the German problem in post-war Europe, and also put a strong impact on the position of Prussia in historical memory of Germans after 1990.

\section{REFERENCES}

1. Dann, O. (2003) Natsii $i$ natsionalizm v Germanii, 1770-1990 [Nation and Nationalism in Germany, 1770-1990]. Translated from German by I.P. Streblova. St. Petersburg.

2. Orlow, D. (2006) The GDR's failed search for a National Identity, 1945-1989. German Studies Review. 29(3). pp. 537-558.

3. Documentarchiv.de. (n.d.) Mitteilung über die Dreimächtenkonferenz von Berlin (Potsdamer Abkommen) vom 2. August 1945. [Online] Available from: http://www.documentarchiv.de/in/1945/potsdamer-abkommen.html. (Accessed: 16th January 2015).

4. Germany. (1947) Gesetz Nr. 46 des Alliierten Kontrollrates in Deutschland über die Auflösung des Staates Preußen, 25. Februar 1947. [Online] Available from: https://www.1000dokumente.de/pdf/dok_0231_pre_de.pdf. (Accessed: 30th July 2018).

5. Bauer, F.H. (1999) Bundeswehr und Nationale Volksarmee in der Aufstellungsphase 1947 bis 1956. Eine vergleichende Studie. Dissertation. Frankfurtam-Main.

6. Neues Deutschland. (1947) 1st March.

7. Betmakaev, A.M. (2003) On the way to East German identity: W. Ulbricht and relations between the German Democratic Republic and the USSR in 1949-1964. In: Lekarenko, O.G. \& Pelipas, M.Ya. (eds) Amerikanskie issledovaniya v Sibiri [American Studies in Siberia]. Vol. 7. Tomsk: Tomsk State University. [Online] Available from: http://hist.asu.ru/aes/gdr/btmkv.htm. (Accessed: 12th August 2018). (In Russian).

8. Münkler, H. (2009) Die Deutschen und ihre Mythen. Berlin: Rowohlt.

9. Neues Deutschland. (1948) 16th June.

10. Märkische Volksstimme. (1959) 14th November.

11. Märkische Volksstimme. (1968) 25th May.

12. Das Volk. (1962) 27th January.

13. GDR. (1949) Verfassung der Deutschen Demokratischen Republik vom 7. Oktober 1949. [Online] Available from: http://www.verfassungen.de/ de/ddr/ddr49-i.htm. (Accessed: 17th July 2018).

14. Neues Deutschland. (1962) 15th June.

15. Neues Deutschland. (1953) 9th June.

16. Neues Deutschland. (1996) 12th February.

17. Germany. (1965) Protokoll der Sitzung des Nationalen Verteidigungsrates von October 13, 1965. [Online] Available from: http://www.nationalerverteidigungsrat.de/downloads/findbuch.pdf. (Accessed: 17th July 2018).

18. GDR. (1968) Verfassung der Deutschen Demokratischen Republik vom 9. April 1968. [Online] Available from: http://www.verfassungen.de/ de/ddr/ddr68-i.htm. (Accessed: 19th July 2018).

19. Wippermann, W. (2011) Preußen: kleine Geschichte eines großen Mythos. Freiburg im Breisgau: Herder.

20. Wiechmann, G. (1997) Das Preußenbild in der DDR-Medien: DEFA-Spielfilm "Lützower". In: Waterkamp, R. (ed.) Der Wandel des Preußenbildes in den DDR-Medien. Bonn: Bundeszentrale für politische Bildung. pp. 49-70.

21. Mayers, P. (1997) Die DDR-Fernsehproduktion "Scharnhorst". In: Waterkamp, R. (ed.) Der Wandel des Preußenbildes in den DDR-Medien. Bonn: Bundeszentrale für politische Bildung. pp. 70-84.

22. Mittenzwei, I. (1979) Friedrich II. von Preußen. Eine Biographie. Berlin: [s.n.].

23. Neues Deutschland. (1971) 12th May.

24. Gröhler, O. (1981) Die Kriege Friedrichs II. Berlin: [s.n.].

25. Helmert, H. \& Usczeck, H. (1975) Preußischdeutsche Kriege von 1864 bis 1871. Berlin: [s.n.].

26. Rus, E.V. (n.d.) Istoricheskaya preemstvennost' kak element natsional'noy identichnosti v istoriografii FRG $i$ GDR [Historical continuity as an element of national identity in the historiography of the FRG and the GDR]. [Online] Available from: http://www.rusgermhist.ru/documents/ isledovateli/feling/Kontinuitat2.pdf. (Available from: 15th July 2018).

27. Petelin, B.V. \& Stepanov, G.V. (2013) Erikh Khonekker [Erich Honecker]. Voprosy istorii. 9. pp. 117-128.

28. Ash, T.G. (1981) Bei den Roten Preußen: wie ein Engländer die DDR erlebt (III). Spiegel. 16th November. pp. 196-208.

29. Neues Deutschland. (1980) 5th June.

30. Neues Deutschland. (1983) 12th November.

31. Neues Deutschland. (1986) 29th September.

32. Neues Deutschland. (1984) 21 st July.

33. Neues Deutschland. (1988) 16th January.

34. Neues Deutschland. (1981) 15th September.

35. Spinder, S. (1997) Preußen in den DDR-Medien, dargestellt am Beispiel von Sachsens Glanz und Preußens Gloria. In: Bundeszentrale für politische Bildung Bonn. Der Wandel des Preußenbildes in den DDR-Medien. Bonn: Bundeszentrale für politische Bildung.

36. Gintsberg, L.I. (1988) Fridrikh II. Voprosy istorii. 11. pp. 98-118.

37. Thum, G. (2010) "Preußen - das sind wir!": Zur Wiederentdeckung der preußischen Kulturlandschaft in Deutschland und Polen. Zeitschrift für Ostmitteleuropa-Forschung. 59(3). pp. 301-322. 